\title{
La funcionalidad, si existe, no deriva de un propósito. Una argumentación desde la biomorfodinámica y la evo-devo
}

\author{
Functions do not derive from a purpose. \\ An argument from biomorphodinamics and evo-devo
}

\author{
MIQUEL DE RENZI \\ Instituto Cavanilles de Biodiversidad y Biología Evolutiva. \\ Universitat de València (España)
}

\section{RESUMEN}

La noción de propósito es inherente a la finalidad (adaptación, función) si se toma ésta como causa principal de las estructuras orgánicas. Éstas surgen a través del desarrollo, que tiene una causalidad propia, sin propósito con respecto al organismo adulto. El desarrollo esta canalizado y sujeto a limitaciones (constraints); por ello, no se alcanzan óptimos adaptativos en general. Sobre tales posibilidades limitadas en variabilidad actúa la selección natural; la modularidad permite combinar selectivamente aspectos independientes, pero siempre dentro de limitaciones. Pueden surgir estructuras no funcionales que llegarán -o no- a constituir exaptaciones, que serán el paso previo a toda adaptación.

PALABRAS-CLAVE

\section{ADAPTACIONISMO, EXAPTACIÓN, CANALIZACIÓN, LIMITACIÓN DE DESARROLLO, MODULARIDAD}




\begin{abstract}
The notion of design is inherent to finality (adaptation, function) if this last one is taken as the main cause of organic structures. Structures arise throughout development, which has its own causation, decoupled from the design referred to the adult organism. Development is canalized and subjected to constraints; because of this, adaptive optima are not generally reached. Natural selection works on these possibilities of constrained variability; modularity allows the selective combination for independent features, but always within a constrained framework. Nonfunctional structures are expected, which will arrive -or not- to give exaptations, the previous step to any adaptation.
\end{abstract}

KEYWORDS

ADAPTATIONISM, EXAPTATION, CANALIZATION, DEVELOPMENTAL CONSTRAINTS, MODULARITY

\title{
I. INTRODUCCIÓN
}

Estamos aCostumbrados a oír que toda estructura tiene su función en el organismo, lo cual puede inclinarnos a pensar que existe un propósito inherente a las mismas, lo cual ha estado presente en buena parte de la historia de la biología. Si partimos de los cuatro tipos de causas reconocidos por Aristóteles, podemos aplicarlos a la forma orgánica, bien sea a la concha de un molusco, a un diente o a un pulmón. La causa material estará en las células (pulmón) y, para las conchas o dientes, en las proteínas específicas y sustancias orgánicas en general, y los iones. Las fuerzas actuantes (causa eficiente) van desde movimientos celulares a interacciones eléctricas asociadas a las cargas de las proteínas y los iones. Los modelos (causa formal) vendrían dados por los grados de libertad que determinarían los espacios confinantes para las fuerzas; v.g. la cavidad extrapaleal del molusco o la cámara aislada en que tiene lugar la morfogénesis del diente. Una vez ultimada la estructura podría realizar su función (causa final, finalidad) en el organismo: respiración (pulmón), protección o flotación (concha) o procesado de alimento (esmalte dental).

Desde Aristóteles, la finalidad se concibe como algo inherente a los seres vivos y sus estructuras, aunque requiere del concurso de las otras tres causas para que pueda cumplirse, como se concluye de la parábola aristotélica de la casa (Thompson 1942, p. 6). ${ }^{1}$ Immanuel Kant fue su adalid, aunque matizadamente; afirmó que las especies subsanarían la imperfección inicial de sus estructuras hasta lograr la adecuación estricta entre la forma y la función que cumplen (Kant

1 Aristóteles, con el precedente de Platón, pensaba que las causas finales y formales dirigían las eficientes y materiales. La época moderna se distinguió por una inversión de este principio al concebir el mundo como una máquina y no como un organismo (Collingwood, 2006). 
2007, p. 358). Así, todo el mundo tendía a admitir que la función daba razón de los órganos. El enfrentamiento surgió a principios del siglo XIX dentro de la discusión entre Cuvier y Geoffroy Saint-Hilaire: para el primero no existirían órganos sin función, mientras que para el segundo, lo primordial sería la unidad de plan. Si esto último fuera así, la función sería secundaria, ya que el plan único sería compatible con todas las funciones y, en consecuencia, no podría comprometerse con ninguna de ellas (Geoffroy Saint-Hilaire 1830). ${ }^{2}$

Ahora bien, la funcionalidad existe. En la perspectiva evolucionista, Darwin (1859) plantea que la selección natural daría origen a las adaptaciones y a las mejoras funcionales en general. ${ }^{3}$ Sin embargo, para él la unidad de plan no tendría explicación funcional -en coincidencia con Richard Owen- ${ }^{4}$ y, en consecuencia, no habría intervenido la selección (Darwin 1859, p. 435). La versión final de la síntesis evolutiva moderna pasa a ser enormemente adaptacionista y seleccionista; el resto de mecanismos (mutación, migración y deriva genética) son prácticamente irrelevantes (Gould 1980).

El adaptacionismo dominante fue muy criticado por Gould y Lewontin (1979), que argumentaron mediante la Konstruktions-Morphologie (posteriormente biomorfodinámica; Seilacher 1970,1991), cuyos planteamientos tendrían más tarde el soporte de la evo-devo inicial, representada por los trabajos de Pere Alberch, que recuperaban, entre otros, el concepto de canalización de Waddington (1957). ${ }^{5}$ Todo apuntaba a limitaciones (constraints), tanto de morfologías posibles y variabilidad como de capacidad de alcanzar óptimos funcionales.

A la vista de todo lo dicho el problema sigue en pie. Ahora bien, si no admitimos propósito externo en los aspectos funcionales y estos existen, debemos aceptar que en las explicaciones de los mismos nos faltan elementos. Reconocer que surgen estructuras sin uso funcional es uno de los caminos para resolverlo. No obstante, una vez formada la estructura puede resultar útil en algún sentido, aunque ello no ocurra necesariamente; si se da tal utilidad, nos remite al concepto de exaptación de Gould y Vrba (1982). Que estas estructuras

2 La obra citada, junto con la argumentación de Cuvier está accesible en http://books. google.es/books?id=hGE5yMiYjmsC. Cf. asimismo Richards (1992) y De Renzi (2009). Acerca de la historia de la relación entre forma y función, Cf. Ochoa y Barahona (2009).

3 Siempre que se cite a Darwin se refiere a la $1^{\text {a }}$ edición (1859) de On the Origin of Species by Means of Natural Selection. Se ha citado sobre la edición facsímil (1964), por lo que la cita de páginas coincide con la de la edición original.

4 Darwin cita expresamente Owen (1849), cuya traducción al castellano ha aparecido muy recientemente (2012).

5 Los trabajos de Pere Alberch han sido recogidos en edición facsímil en RasskinGutman y De Renzi, eds. (2009), con tres introducciones a su obra científica. Los trabajos que aquí se citarán (Alberch 1980, 1982, 1989 y 1991; Alberch y Gale 1985) están reproducidos en este libro, pero en la bibliografía se dará la revista o la obra en que aparecieron originalmente. 
se generan a causa del desarrollo embrionario, desacoplado de toda relación prospectiva con respecto al estado adulto del organismo, es el otro punto de vista que necesitamos para hacer compatible la presencia de aspectos funcionales en los organismos sin necesidad de acudir a ningún propósito, lo cual facilita comprender que puedan existir rasgos no funcionales. Estas serán las premisas de la argumentación.

\section{PROPÓSITO Y ADAPTACIONISMO}

Ver propósito en la forma orgánica o en su evolución es adoptar un punto de vista antropocéntrico, ya que fabricamos instrumentos u objetos para satisfacer determinadas finalidades. Esto genera un vicio de lenguaje muy grave: se pregunta por qué existe una estructura, lo cual implicaría las causas material, eficiente y formal, y se responde con un para, que implica hablar de la causa final (De Renzi 2012); v.g. la pluma existe para proporcionar la homeotermia a sus portadores, cuando su existencia resulta de un proceso morfogenético (cf. Edelman 1988, pp. 32-35; Prum 1999, Prum y Brush 2002) independiente de su función posterior. ${ }^{6}$ El uso de para implica que hay una finalidad previa y, por tanto, un propósito. Sólo la idea de preformación, con su sustrato creacionista (cf. Richards 1999, p.12), mostraría una intencionalidad (la del creador). Otra cosa es que tal proceso morfogenético haya sido seleccionado porque su resultado -la pluma- conlleva la homeotermia.

Lo dicho podría inducirnos a pensar que el desarrollo, en términos de epigénesis, ${ }^{7}$ diera lugar a toda clase de estructuras. Sin embargo, esto no es así. La conservación del Bauplan se funda en la estabilidad del desarrollo embrionario, difícilmente modificable durante el transcurso de la evolución. Esta estabilidad, según Alberch (1980, 1982), se basa en la dinámica no lineal del proceso, con dominios altamente estables de variación restringida, cuya transición de unos a otros se hace por discontinuidades, lo que es propio de la mayoría de sistemas naturales. Por este motivo, Alberch (1989) sugirió que se comprendería mejor la naturaleza desde una filosofía dialéctica hegeliana, a diferencia de la dominante, que implica continuidad. Se ha de añadir que tales dominios estarían establecidos desde el origen de los grupos en su práctica totalidad y que, por tanto, únicamente podemos esperar novedades menores.

6 Recordemos que, históricamente, el desarrollo se pensaba que estaba dirigido por un telos (Richards 1992; p. 23); es decir, que la causa final regiría sobre la eficiente y la material, en una reminiscencia de la concepción de la naturaleza como un organismo y no como máquina (Collingwood 2006); justamente al revés de lo que se va a defender aquí.

7 La epigénesis fue siempre vista como algo suspecto desde el punto de vista teológico, al invocar para su realización una fuerza (vis plastica) con poderes, se podría decir, demiúrgicos y, por tanto, sin necesidad de un creador (cf. Richards 1992, p. 10; De Renzi 2009, pp. 29-30). 
El programa adaptacionista propone la funcionalidad de toda estructura ${ }^{8}$ sus premisas son (Gould y Lewontin 1979): (1) concepción «atomizada» del organismo (órganos con funciones optimizadas). Si ello fracasa, (2) visión integrada del organismo y estructuras con más de una función (óptimos condicionados). Si también fracasa, entonces (3) se alega ignorancia de parte o todas las condiciones ambientales y por eso no se puede explicar la función de una estructura en su medio. Finalmente, (4) se tiende a asignar una función inmediatamente a una estructura; si nuevas observaciones la refutan, se le asigna otra. En definitiva, en cada parte del organismo subyace un propósito. Son Gould y Lewontin (op. cit.) quizá los primeros en primar el desarrollo y su carácter limitante por encima de las explicaciones adaptacionistas en evolución; v.g. si la selección a favor de un campo morfogenético conlleva la reducción de otro, esto último no originará necesariamente una nueva adaptación. Esta afirmación vulneraría (2) -no alcanzar óptimos adaptativos- y (4) - explicación adaptativa innecesaria.

\section{APTACIÓN, EXAPTACIÓN Y ADAPTACIÓN}

Las dos primeras nociones fueron desarrolladas por Gould y Vrba (1982), a fin de clarificar qué es producto de selección natural y qué no lo es y, en cambio, presta un servicio a la supervivencia del organismo. De la lectura de Darwin (1859), se desprende que la adaptación resulta de modelar una estructura, para el papel que cumple en aquel momento, por selección natural de las variantes hereditarias existentes en la población. Ese papel es el servicio que la estructura presta al organismo para su supervivencia y se le conoce como su función.

Sin embargo, existen 1) estructuras que surgen de novo (novedades) y tienen, o no, un papel inmediato en la supervivencia; o existen 2) estructuras con una función muy concreta, producto de la selección, en una situación anterior, pero que son usadas en circunstancias distintas y prestan a su portador un servicio diferente al original. Tanto para un tipo de estructuras como para el otro, los autores acuñan el término exaptación. La exaptación se caracteriza por 1) prestar un servicio a su portador en orden a asegurar su supervivencia, y 2) no ha sido el resultado de la selección natural para adecuarse a aquella finalidad concreta. A dicho servicio lo denominan efecto. Ambas, adaptación y exaptación, las denominan aptaciones.

8 Ver también Caponi (2011) acerca de cómo surge históricamente un programa adaptacionista asociado con la teoría evolutiva. Sin embargo, mi trabajo alude más a los vicios generados por el adaptacionismo que a los errores de percepción que denuncia Caponi acerca de cómo ha surgido. Una crítica al discurso puramente adaptacionista y optimizador (telling stories; Gould y Lewontin 1979) la hace Frazzetta (1975; capítulo 5), así como Rudwick (1964) destaca la ausencia de planteamientos cuantitativos a la hora de hacer asignación de funciones a una estructura y a la falta de contrastación en que se incurre. 
Finalmente, existen estructuras subproducto, como el caso de la reducción de órganos citado anteriormente, u otras surgidas de novo que no prestan inicialmente servicio de ningún tipo al organismo: son las no-aptaciones. Hasta aquí, las ideas básicas.

Ahora bien, una exaptación con variantes hereditarias, sobre las que actúe la selección natural, puede mejorar sus efectos, con lo cual estos pasan a ser funciones, y lo que era una exaptación adquiere el estatus de adaptación. En definitiva, podría decirse que tras toda adaptación existiría una exaptación previa. Ello ocurre porque toda estructura implicada en algún servicio al organismo, o bien ha surgido de novo y no ha estado sujeta a selección, como sería la pluma en su origen, cuyo primer efecto fue contribuir a la homeotermia de su portador; o bien ha estado implicada en una función diferente, por selección, en otras condiciones. Si bien en este último caso la selección actuó para adecuar la estructura a la función correspondiente, en las nuevas condiciones todavía no lo habría hecho, aunque fuera útil para dicha situación como efecto. Podríamos pensar en las aletas de los primeros tetrápodos (Shubin et al.2006, Coates et al. 2008), modeladas para desplazarse en el agua y que pasan a ser útiles (efecto) para la locomoción en el medio terrestre, con toda la gama de adaptaciones posteriores que ello comportó.

\section{BIOMORFODINÁMICA, DESARROLLO Y AUTOORGANIZACIÓN}

La biomorfodinámica se ha convertido en un marco conceptual adecuado para estudiar la forma orgánica y su evolución en los términos de los factores que la rigen: histórico, de fabricación y funcional en el contexto del ambiente efectivo (Seilacher, 1991). El factor histórico es conocido también como legado filogenético: a pesar de todas las mutaciones que se hayan producido a partir del genoma ancestral, su expresión está regulada por el desarrollo embrionario, que es muy estable (ver más arriba) y mantiene el Bauplan (causa formal); también los biomateriales asociados (causa material); v.g. celulosa, cerámicas biológicas, etc., prácticamente inmodificables (llegan a caracterizar grupos enteros; así, la celulosa en las plantas), forman parte del factor histórico, si bien en este último caso los genes tienen un peso mucho mayor. La carga filogenética constituirá, pues, una seria limitación para las adaptaciones.

Sin embargo, el desarrollo es la sede de la producción de forma o morfogénesis (que incluirá el comportamiento fisicoquímico de los biomateriales) al ser un proceso de interacción entre la expresión de los genes y los acontecimientos epigenéticos que determina, sobre todo de carácter mecánico-químico. A esto se refiere el factor de fabricación. Dicho factor prescribe las estructuras que pueden surgir y cómo se construyen o fabrican (causa eficiente). Tendríamos pues dos tipos de restricciones (constraints) sobre las posibilidades adaptativas: las impuestas por la constancia del Bauplan (aspectos históricos) y las debidas a 
la pura obediencia a las leyes de la física y de la química (aspectos ahistóricos) impuestas por la fabricación (Reif et al. 1985). En ese marco, el organismo construye sus estructuras funcionales (f. funcional) que, a su vez, son probadas en el ambiente efectivo.

Es evidente que los dos primeros factores están vinculados a la biología evolutiva del desarrollo (evo-devo), pero en su versión inicial -la que podríamos hallar en Alberch $(1980,1982)$ o Edelman (1988) - y no tanto la de la primacía de la genética del desarrollo, sobre la cual se ha puesto finalmente el énfasis. Alberch ha hecho siempre mención explícita de que su argumentación se basaba, entre otras, en la noción de canalización de Waddington, con la idea de paisaje epigenético (Fig. 1A): el desarrollo se ve obligado a seguir unas pocas vías canalizadas, o creodos, de las cuales es muy difícil salirse. ${ }^{9}$ En todo caso, se pasa de una vía a otra mediante un salto. La idea de canalización se basa en un gran acúmulo de evidencias empíricas de perturbaciones del desarrollo, tanto ambientales como internas (cambios genéticos).

En referencia al papel de los genes durante el desarrollo, podríamos decir que ellos ponen los productos génicos y éstos interactúan epigenéticamente, con los consiguientes efectos en cascada que acabarán traduciéndose en forma. Los estados transitorios de forma durante el desarrollo tienen capacidad para evocar nuevas secuencias de regulación y expresión génica; v.g. ello ocurre si llegan a ponerse en contacto o en proximidad unos tejidos con otros (inducción, difusión de morfógenos). El proceso de desarrollo no está regido jerárquicamente por los genes sino que se trata de un proceso cibernético (Fig. 1B), por el cual, si bien los genes se expresan durante el desarrollo, dicha expresión está bajo control epigenético (Alberch 1989, 1991; acontecimientos mecánico-químicos, Edelman 1988).

Ahora bien, muchos efectos en cascada consisten en el despliegue de procesos de autoorganización en pura obediencia a las leyes de la física y de la química (fabricación) en el periodo de desarrollo, y sin finalidades prospectivas (cf. nota 6). La autoorganización se da sólo en sistemas abiertos y bastante alejados del equilibrio (termodinámica no lineal). Las estructuras resultantes surgen del caos y el desorden a partir de inestabilidades internas y tienen carácter disipativo. El orden se hace manifiesto y surge una jerarquización de estructuras (Sheliepin 2005). Es así como surgen las novedades evolutivas mencionadas antes; v.g. la pluma, el esmalte dental, etc.

9 Alberch no habló expresamente de morfología construccional, pero con sus ideas dio fundamento para identificar como limitación histórica la estabilidad del desarrollo durante la filogenia; se puede ver, en términos de revisión, mi trabajo en Rasskin-Gutman y De Renzi, eds. (2009; pp. 45-66). 


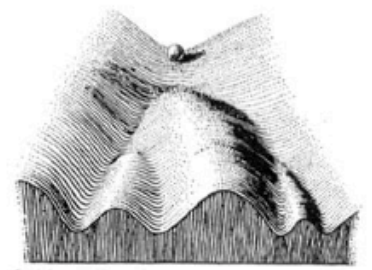

A

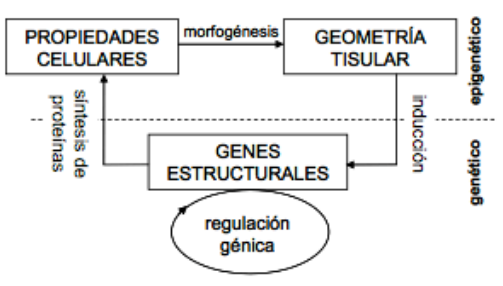

B

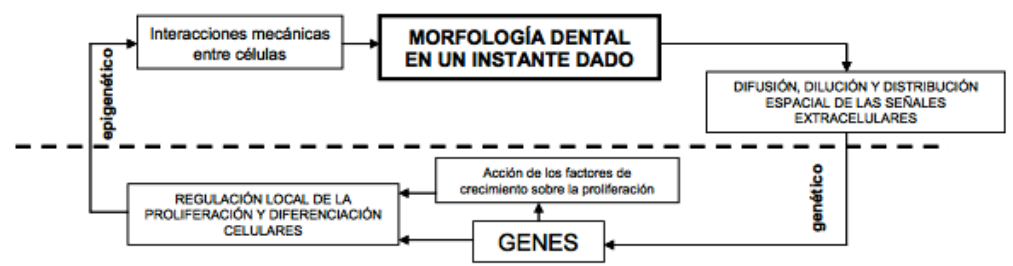

C

Figura 1. A. El paisaje epigenético (Waddington 1957). B. La relación cibernética entre expresión génica y desarrollo (redibujado de diversos esquemas similares de Alberch; v.g. Alberch 1991). C. Interpretación de las relaciones propuestas por Salazar-Ciudad (2008). Compárese con el esquema B.

Finalmente, comentaré otro aspecto propio los Baupläne, la homología. La conservación del Bauplan, de la que ya se habló anteriormente, se expresa en la conservación de los órganos y estructuras homólogos, que implican su disposición general. Las homologías gozan de una gran estabilidad, sin compromiso con ninguna función específica; v.g. las extremidades de los tetrápodos (Geoffroy Saint-Hilaire 1830; ver «Introducción»). Las conexiones del complejo de piezas se mantienen topológicamente, aunque estas puedan experimentar una gran variedad de cambios en tamaño y proporción. Müller (2003) puso de manifiesto que no existe una causa única que dé razón de la perpetuación de las homologías, ni genética (en términos de genes compartidos) ni de desarrollo (interacciones inductivas o trayectorias ontogenéticas), aspectos todos modificables a través de la evolución. Para Müller existen tres fases o estadios en la configuración evolutiva de la homología: la generativa (aparición de la novedad morfológica); la integrativa (conservación de la novedad al menos en una especie descendiente); y, finalmente, la autónoma (independizarse de los mecanismos subyacentes -genéticos, desarrollo...- de las fases anteriores). Por todo ello, no existen definiciones de homología que se puedan basar ni en la genética ni en el desarrollo embrionario. Esta constancia en la construcción del organismo, según Müller, ya fue percibida por Richard Owen. La conclusión a que llega 
Müller (op. cit.) es que las estructuras homólogas actúan como organizadores (organizers) del fenotipo; debo comentar que este concepto de organizador es el mismo que acuñó Spemann en colaboración con Mangold (Jahn et al. 1990). Es obvio que toda vinculación entre tal principio y los estados finales funcionales es inexistente.

\section{Modelos MORfogenéticos, eStAdos FINALES Y LIMITACIONES QUE SE DERIVAN}

Estructuras muy distintas implicadas en diversas funciones o efectos se fabrican mediante unos pocos mecanismos morfogenéticos simples. Sin embargo, su causalidad se centra en la inherente a los procesos del desarrollo, sin relación con la posible funcionalidad en el estado adulto de las estructuras que generan. Me centraré sobre las microestructuras de las conchas o dientes, y en los relieves de las coronas dentales de los mamíferos, pero también examinaré las posibles limitaciones que pueden surgir para las posibilidades adaptativas.

Las microestructuras proceden de procesos de biomineralización con una base común a todos los organismos que construyen cerámicas biológicas (estructuras mineralizadas): un juego entre macromoléculas hidrófobas e hidrófilas que origina una matriz extracelular altamente ordenada; dicha ordenación se puede obtener in vitro, ya que obedece únicamente a las leyes físico-químicas. Esa matriz regula la nucleación cristalina, el crecimiento y la forma de los cristales minerales que se forman en ella (Margolis et al. 2006). Las interacciones proteína-proteína y proteína-iones inorgánicos $\left(\mathrm{Ca}^{2+}, \mathrm{PO}_{4}^{3-}, \mathrm{CO}_{3}{ }^{2-}\right)$ constituyen el proceso de autoorganización -self-assembling; Margolis et al. 2006-, que se inicia con una disminución local de entropía y termina con una jerarquización de estructuras (Sheliepin 2005), con la emergencia de propiedades mecánicas muy importantes relacionadas con la resistencia a la rotura o al desgaste (para el esmalte dental, cf. Lucas et al. 2008). Sin embargo, el proceso se realiza en obediencia a las leyes de la física y de la química, sin relación final con el organismo adulto. En principio, las microestructuras, si útiles, tuvieron el carácter de exaptaciones.

El otro caso a comentar, los relieves de las coronas dentales de los mamíferos, obedece a otro modelo puramente físico-químico, como es el de reacción-difusión, concebido por Turing (1952) y perfeccionado posteriormente (cf. Nijhout 2003). Se debe indicar que si bien el esmalte está mineralizado y a penas posee materia orgánica (se digiere durante su formación), los relieves que presenta corresponden en realidad al epitelio que actúa como molde o matriz sobre el cual se forma. Por lo tanto, el esmalte simplemente refleja la morfología del tejido vivo que le sirve de base y lo que se va a decir vale para la morfología de cualquier órgano o estructura orgánica. Durante la morfogénesis de los repliegues de dicho epitelio, un activador autocatalítico de corto alcance se difunde, activa de algún modo determinadas células del esbozo embrionario y 
favorece la formación de un inhibidor de largo alcance que frena lateralmente la síntesis de activador. Salazar-Ciudad (2008) ha desarrollado un modelo de este tipo para explicar las cúspides y los valles de las coronas dentales en ratones. En el fondo, subyace la relación cibernética genético-epigenético (Fig. 1C). Se sabe que estas cúspides (en otros casos, crestas, etc.) tienen una importancia funcional considerable para el régimen trófico de los mamíferos; en su origen hay simples procesos físicos de difusión, con sus conocidas expresiones matemáticas, y activación e inhibición al nivel molecular. ${ }^{10}$ Sin embargo, el resultado conduce a la emergencia de propiedades vinculadas al procesado efectivo del alimento. Por lo tanto, en su origen debieron constituir exaptaciones.

Asociadas con los modelos de reacción-difusión se dan una serie de restricciones (constraints) que impiden el surgimiento de determinados patrones. Los patrones de coloración (pelaje, conchas, insectos) obedecen a estos modelos. En el caso de los pelajes (tigre, leopardo, pero también vaca), el dominio geométrico de determinadas partes de la piel embrionaria parece prescribir obligatoriamente un patrón de color; v.g. los animales listados (cebra, tigre) tienen, a su vez, la cola en franjas de pigmento (listas anulares). Sin embrago, si está moteado (jineta), nunca aparecen motas en su cola sino listas anulares, algo que los modelos de reacción-difusión también muestran como condiciones impuestas por la geometría cónica de la cola a los procesos de difusión (Murray 1981). Esto significa que la geometría embrionaria impone, a su vez, limitaciones en la expresión fenotípica bajo este tipo de modelos tan ubicuo y que, por tanto, también las imponen a las posibilidades adaptativas.

\section{MODULARIDAD, VÍAS ABIERTAS A LA SELECCIÓN Y DICTADOS INTERNOS}

Finalmente, queda por tocar la cuestión de la modularidad. Si tomamos como definición de sistema modular (Callebaut 2005), aquél cuyos componentes poseen una cierta independencia en su modo de acción, con sus propios principios intrínsecos, nos daremos cuenta que, dentro de las limitaciones, la selección natural puede operar combinatoriamente.

10 A título de descripción, reproduciré el modelo 1 de dicho autor. Éste consta de un sistema de dos ecuaciones en derivadas parciales:

$$
\begin{aligned}
\frac{\partial[A]}{\partial t} & =\frac{k_{1}[A]}{k_{2}[I]+1}+k_{3}+D_{A} \nabla^{2}[A] \\
\frac{\partial[I]}{\partial t} & =[A]+D_{I} \nabla^{2}[I]
\end{aligned}
$$

Donde $[\mathrm{A}]$ e $[\mathrm{I}]$ representan las concentraciones del activador $A$ y el inhibidor $I$. Los primeros miembros de las ecuaciones describen sus concentraciones en el tiempo; $k_{1}, k_{2}$ y $k_{3}$ son constantes, junto con los coeficientes de difusión $D_{A}$ y $D_{I}$ del activador y el inhibidor, mientras que los términos con el operador $\Delta^{2}$ describen espacialmente la difusión del activador y el inhibidor. 
La variabilidad de las expresiones finales resultante del desarrollo de los módulos, si es hereditaria, permitirá que la selección asocie ciertas variantes de uno o más módulos con ciertas de otros. Si se piensa en los miembros de los tetrápodos como dos pares de módulos distintos, dos anteriores y dos posteriores, la evolución nos muestra formas con los anteriores menos desarrollados que los posteriores (muchos dinosaurios y mamíferos terrestres) y viceversa (pterosauros, ictiosauros y mamíferos marinos). Lo mismo podemos decir si consideramos como módulos las distintas partes del quiridio (estilópodo, zeugópodo y autópodo): podemos observar el desarrollo exagerado del cuarto dedo y el casi vestigial de los otros tres en Rhamphorhynchus y Pteranodon (pterosaurios) o de cuatro de los dedos en los quirópteros (euterios).

Se podría decir que la selección ha actuado según vías diferentes en los distintos módulos. Sin embargo, también cabe pedirse hasta qué punto las variaciones no fueron un producto de la dinámica interna en cada caso, como se muestra en Alberch y Gale (1985) en referencia a la pérdida de dedos -si ocurre-en anuros (ranas) y urodelos (salamandras) durante la evolución, como algo ya fijado en ambos clados (del primero en anuros y de postaxiales en urodelos). Finalmente, la modularidad, vuelve a dar una razón más para pensar que la función no precede sino que sigue a la forma en el sentido de Geoffroy SaintHilaire, a la inversa de la postura neodarwinista más extendida; si se atiende al morfoespacio modular teórico, éste muestra que contiene zonas teóricamente imposibles (Rasskin-Gutman 2005, p. 214-216), con lo cual se vuelve al principio de la argumentación aquí seguida.

\section{CONCLUSIÓN}

Como punto final, se debe decir que, tanto en un caso como en el otro, el desarrollo se da aislado del medio externo (internalismo), con una causalidad independiente de los estados finales, y sus consecuencias serían, en principio, exaptaciones (con efectos) o, finalmente, adaptaciones (con funciones) si interviene la selección natural sobre los aspectos hereditarios que influyen sobre los parámetros del proceso, a lo cual habría que añadir las limitaciones impuestas por el desarrollo; v.g. los resultados de los procesos de activación-difusión dependen en gran medida de la geometría del dominio embrionario en donde tienen lugar y ello conduce, según qué geometría, a resultados imposibles. Estas limitaciones pueden venir aliviadas por la modularidad; entonces la selección puede promover la integración de rasgos a causa de la independencia parcial de los módulos en cuanto a su desarrollo, aunque se pueden prever ciertas direccionalidades fijadas internamente en el origen de los distintos clados. Sin embargo, la resultante de estos procesos puede conducir a no-aptaciones, ya que los mismos tienen sus propias leyes, independientemente de las finalidades 
posteriores. Con lo dicho hasta aquí, queda claro que no todo es funcionalidad, ni existe propósito, ni, en su caso, se alcanzan los óptimos.

\section{AgradeCIMIENTOS}

Este trabajo se encuadra en el proyecto CGL2010-15326 (subprograma BTE) del Ministerio de Ciencia e Innovación de España.

\section{REFERENCIAS BIBLIOGRÁFICAS}

ALBERCH, P. (1980) «Ontogenesis and Morphological Diversification», American Zoologist, 20, pp. 653-667.

, (1982) «Developmental Constraints in Evolutionary Processes», en J.T. Bonner (ed.) Evolution and Development, Berlín, Dahlem Konferenzen, Springer-Verlag, pp. 313-332.

,(1989) «The Logic of Monsters: Evidence for Internal Constraint in Development and Evolution», Geobios, mémoire spécial 12, pp. 21-57.

, (1991) «From genes to phenotype: dynamical systems and evolvability», Genetica, 84, pp. 5-11.

, y GALE (1985) «A developmental analysis of an evolutionary trend: digital reduction in amphibians», Evolution, 39(1), pp. 8-23.

CALLEBAUT, W. (2005) «The Ubiquity of Modularity», en W. Callebaut y D. RasskinGutman (eds.) Modularity: Understanding the Development and Evolution of Natural Complex Systems, Cambridge, Mass., The Vienna Series in Theoretical Biology, The MIT Press, pp. 3-28.

CAPONI, G. (2011) La segunda agenda darwiniana: contribución preliminar a una historia del programa adaptacionista, México D. F.: Centro de Estudios Filosóficos, Políticos y Sociales Vicente Lombardo Toledano.

COATES, M. I., RUTA, M. y FRIEDMAN, M. (2008) «Ever since Owen: Changing Perspectives on the Early Evolution of Tetrapods», Annual Review of Ecology, Evolution, and Systematics, 39, pp. 571-592.

COLLINGWOOD, R. G. (2006) Idea de la naturaleza (trad. E. Ímaz), México: Fondo de Cultura Económica. 
DARWIN, C. (1859) On the Origin of Species by Means of Natural Selection. A Facsimile of the First Edition with an Introduction by Ernst Mayr (1964), Cambridge, Mass.: Harvard University Press.

DE RENZI, A. (2009) «Cuestiones de forma: desde el pensamiento de Darwin hasta la actualidad», en P. Palmqvist y J. A. Pérez-Claros (eds.) Libro de Resúmenes de las XXV Jornadas de la Sociedad Española de Paleontología, Málaga, Universidad de Málaga, pp. 26-50.

, (2012) «Contra el adaptacionismo: morfogénesis y autoorganización no poeseen propósito», en C. Martínez-Pérez, M. Furió, A. Santos-Cubedo y B. Poza (eds.) Paleodiversity and Paleoecology of Iberian Ecosystems. X EJIP. Libro de Resúmenes (,pp. 31-36. Ministerio de Economía y Competitividad e Institut Català de Paleontologia, Imprenta Sichet.

EDELMAN, G. (1988) Topobiology: an Introduction to Molecular Embryology, Nueva York: Basic Books.

FRAZZETTA, T. H.(1975) Complex adaptations in evolving populations, Sunderland, Mass.: Sinauer Associates, Inc.

GEOFFROY SAINT-HILAIRE, E. (1830) Principes de Philosophie Zoologique, discutés en mars 1830 au sein de l'Académie Royale des Sciences, París.

GOULD, S. J. (1980) «G. G. Simpson, Paleontology, and the Modern Synthesis», en E. Mayr y W. B. Provine (eds.) The Modern Synthesis: Perspectives on the Unification of Biology, Cambridge, Mass., Harvard University Press, pp. 153-172.

GOULD, S. J. y LEWONTIN, R. C. (1979) «The Spandrels of San Marco and the Panglossian Paradigm: a Critique of the Adaptationist Programme», Proceedings of the Royal Society of London, B205, pp. 581-598.

GOULD, S.J. \& VRBA, E.S. (1982) «Exaptation -A missing term in the science of form», Paleobiology 8, pp. 4-15.

JAHN, F., LOTHER, R. y SENGLAUB, K. (1990) Historia de la biología: teorías, métodos, instituciones y biografías breves, Barcelona: Editorial Labor, S.A.

KANT, I. (2007) Crítica del Juicio (trad. M. García Morente de la edición original), Madrid: Los Esenciales de la Filosofía, Tecnos.

LUCAS, P., CONSTANTINO, P., WOOD, B. y LAWN, B. (2008) «Dental enamel as a dietary indicator in mammals», Bioessays, 30, pp. 374-385.

MARGOLIS, H. C., BENIASH, E. y FOWLER C. F. (2006) «Role of Macromolecular Assembly of Enamel Matrix Proteins in Enamel Formation», Journal of Dental Research, 85(9), pp. 775-793.

MÜLLER, G.B. (2003) «Homology: the Evolution of Morphological Organization», en G.B. Müller y S.A. Newman (eds.) Origination of Organismal Form: Beyond the Gene in Developmental and Evolutionary Biology, Cambridge, Mass., The Vienna Series in Theoretical Biology, The MIT Press, pp. 51-69.

MURRAY, J. D. (1981) «On pattern formation mechanisms for lepidopteran wing patterns and mammalian coat markings», Philosophical Transactions of the Royal Society of London, B295, pp. 473-496.

NIJHOUT, F. (2003). «Gradients, Diffusion, and Genes in Pattern Formation», en G.B. Müller y S.A. Newman (eds.) Origination of Organismal Form: Beyond the Gene 
in Developmental and Evolutionary Biology, Cambridge, Mass., The Vienna Series in Theoretical Biology, The MIT Press, pp.165-181.

OCHOA, C. y BARAHONA, A. (2009) Forma versus Función: Historia de la Homología y la Analogía, México: Universidad Nacional Autónoma de México, Facultad de Ciencias.

OWEN, R. (2012) Discurso sobre la naturaleza de las extremidades (trad. S. Balari de la edición de 1849). Oviedo: KRK ediciones Pensamiento.

PRUM, R. O. (1999) «Development and evolutionary origin of feathers», Journal of Experimental Zoology, 285, pp. 291-306.

PRUM, R. O. y BRUSH, A. H. (2002) «The evolutionary origin and diversification of feathers», The Quarterly Review of biology, 77, pp. 261-295.

RASSKIN-GUTMAN, D. (2005) «Modularity: Jumping Forms within Morphospace», en W. Callebaut y D. Rasskin-Gutman (eds.) Modularity: Understanding the Development and Evolution of Natural Complex Systems, Cambridge, Mass., The Vienna Series in Theoretical Biology, The MIT Press, pp.207-219.

, y DE RENZI, M. (2009) Pere Alberch: the Creative Trajectory of an Evo-Devo Biologist, Valencia: Institut d'Estudis Catalans y Publicaciones de la Universitat de València.

REIF, W.E., THOMAS, R. y FISCHER, M.S. (1985) «Constructional Morphology: the Análisis of Constraints in Evolution», Acta Biotheoretica, 34, pp. 233-248.

RICHARDS, R.J. (1992) The meaning of evolution: the morphological construction and ideological reconstruction of Darwin's theory. Chicago: The University of Chicago Press.

RUDWICK, M. J. S. (1964) «The inference of function from structure in fossils», British journal of Philosophy of Science, 15, pp. 27-40.

SALAZAR-CIUDAD, I. (2008) «Tooth Morphogenesis in vivo, in vitro, and in silico», Current Topics in Developmental Biology, 81, pp. 341-371.

SEILACHER, A. 1970. «Arbeitskonzept zur Kontruktions-Morphologie», Lethaia, 3, pp. 393-396.

SEILACHER, A. (1991). «Self-organizing Morphogenetic Organisms as Processors of Evolution», Revista Española de Paleontología, n. extr., pp. 5-11.

SHELIEPIN, L. A. (2005) Lejos del equilibrio: sinergética, autoorganización, teoría de las catástrofes, Moscú: Editorial URSS, Libros de Ciencia.

SHUBIN, N. H., DAESCHLER, E. B. y JENKINS, F. A., Jr. (2006) «The pectoral fin of Tiktaalik roseae and the origin of tetrapod limb», Nature, 440, pp. 764-771.

THOMPSON, D’A. W. (1942) On Growth and Form, Cambridge: Cambridge at the University Press.

TURING AM. 1952. «The Chemical Basis of Morphogenesis», Philosophical Transactions of the Royal Society of London, 237, B641), pp. 37-72.

WADDINGTON, C. H. (1957) The strategy of the genes: a discussion of some aspects of theoretical biology, Londres: George Allen \& Unwin, LTD. 
Miquel De Renzi de la Fuente es catedrático de Paleontología e investigador en el Instituto Cavanilles de Biodiversidad y Biología Evolutiva. Universitat de València

Línea de investigación:

Paleobiología evolutiva, sobre todo evolución morfológica y relaciones con evo-devo.

Publicaciones recientes:

FIGUEIRIDO B; MACLEOD N; KRIEGER J; DE RENZI M; PÉREZ-CLAROS JA; PALMQVIST P. 2011. «Constraint and adaptation in the evolution of carnivoran skull shape». Paleobiology 37(3): 490-518.

DE RENZI M. 2009. «Morfología teórica y evolución morfológica». En H. Dopazo \& A. Navarro (eds.) Evolución y adaptación 150 años después del Origen de las Especies. Sociedad Española de Biología Evolutiva, a través de la editorial Obrapropia, Valencia.

Dirección electrónica: miquel.de.renzi@uv.es 